Supplement of Atmos. Chem. Phys., 18, 6121-6139, 2018

https://doi.org/10.5194/acp-18-6121-2018-supplement

(C) Author(s) 2018. This work is distributed under

the Creative Commons Attribution 4.0 License.

(c) (1)

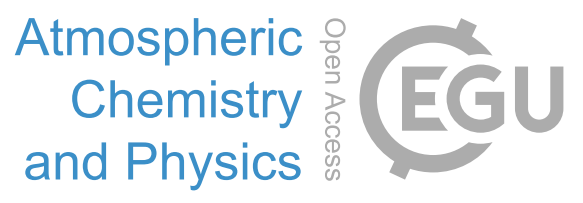

Supplement of

\title{
Key drivers of ozone change and its radiative forcing over the 21st century
}

Fernando Iglesias-Suarez et al.

Correspondence to: Fernando Iglesias-Suarez (figlesias@iqfr.csic.es)

The copyright of individual parts of the supplement might differ from the CC BY 4.0 License. 


\section{Contents of this supporting information}

1. Supporting tables $\mathrm{S} 1$ to $\mathrm{S} 2$.

2. Supporting figures S1 to S4.

\section{Introduction}

This text presents additional information to evaluate the updated ozone radiative kernel $\left(\mathrm{O}_{3} \mathrm{RK}\right)$ and illustrate in more detail present-day tropospheric ozone $(\mathrm{Cnt}$; year 2000), changes in column ozone and temperature due to the different drivers investigated in this study, and additional sensitivity simulations to further assess the robustness of the results presented in the main manuscript. Tables S1 and S2 present global and annual column ozone changes for the above drivers and period, and additional model simulations used in the main text to explore non-linearities respectively. Figure $\mathrm{S} 1$ compares an ozone RF calculated using the $\mathrm{O}_{3} \mathrm{RK}$ technique with the corresponding RF calculated directly with the SOCRATES radiative transfer model, which is based on Edwards and Slingo (1996). Figures S2 and S3 show annual mean tropospheric burden distribution for ozone and stratospheric ozone tracer (O3S) respectively. Finally, Figure S4 shows changes in annual and zonal mean temperature due to climate, lightning, ozone depleting substances (ODSs), and methane over 2000-2100. 
Table S1. Global and annual mean ozone columns (DU) ${ }^{\mathrm{a}}$.

\begin{tabular}{lccc} 
Simulation & Total column & Tropospheric column & Stratospheric column \\
\hline Cnt & $280.6 \pm 8.7$ & $28.9 \pm 1.5$ & $251.7 \pm 8.1$ \\
Clm & $281.5 \pm 9.9$ & $27.7 \pm 1.6$ & $253.8 \pm 9.3$ \\
Ltn & $284.2 \pm 9.7$ & $29.8 \pm 1.7$ & $254.4 \pm 9.1$ \\
O3r & $299.0 \pm 9.5$ & $31.2 \pm 1.7$ & $267.8 \pm 8.8$ \\
Mth & $308.9 \pm 9.5$ & $35.9 \pm 1.9$ & $273.0 \pm 8.8$ \\
Cnt+fLNOx & $280.3 \pm 8.6$ & $28.4 \pm 1.5$ & $251.9 \pm 8.1$
\end{tabular}

${ }^{\mathrm{a}}$ The annual global mean is given along with the $( \pm)$ standard error. 
Table S2. Additional model simulations

\begin{tabular}{lccc}
\hline Simulation & Climate $^{1}$ & ODSs $^{2}$ & $\mathrm{CH}_{4}{ }^{3}$ \\
\hline Clm_Mth & $2100(\mathrm{fLNOx})^{4}$ & 2000 & 2100 \\
Ltn_Mth & 2100 & 2000 & 2100 \\
O3r_Ods & 2000 & 2100 & 2000 \\
\hline
\end{tabular}

${ }^{1}$ Climate (sea surface temperatures, sea ice, $\mathrm{CO}_{2}$ and $\mathrm{N}_{2} \mathrm{O}$, if not otherwise specified) follows the RCP8.5 emissions scenario.

${ }^{2}$ Relative to Cnt, ODS boundary conditions of $-63.2 \%(2.156 \mathrm{ppb})$ total chlorine, $-35.7 \%(8.1 \mathrm{ppt})$ total bromine and $-67.6 \%(1.376 \mathrm{ppb})$ total fluorine follow the halogen scenario A1.

${ }^{3}$ Relative to $\mathrm{Cnt}, \mathrm{CH}_{4}$ boundary conditions of $214.2 \%$ (3744 ppb) follow the RCP8.5 emissions scenario.

${ }^{4}$ Offline lightning-induced $\mathrm{NO}_{\mathrm{x}}$ emissions (fLNOx) are imposed by applying a monthly mean climatology of the Cnt simulation. 


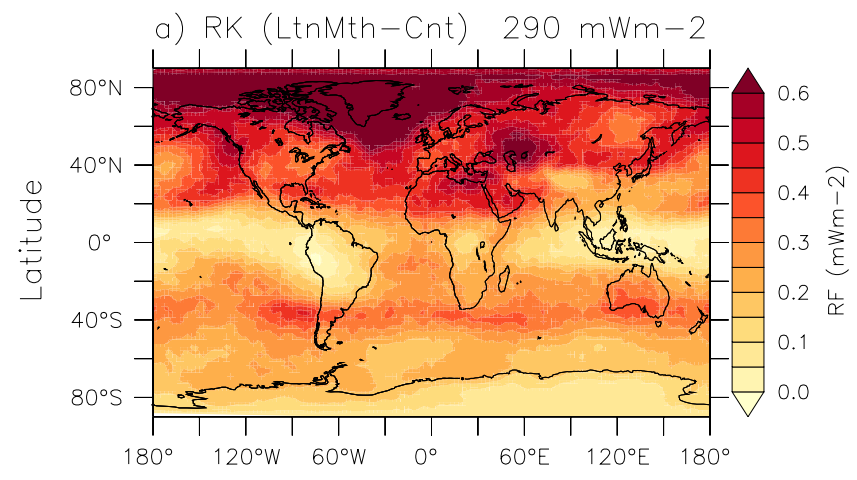

b) RTM (LtnMth-Cnt) $280 \mathrm{mWm}-2$

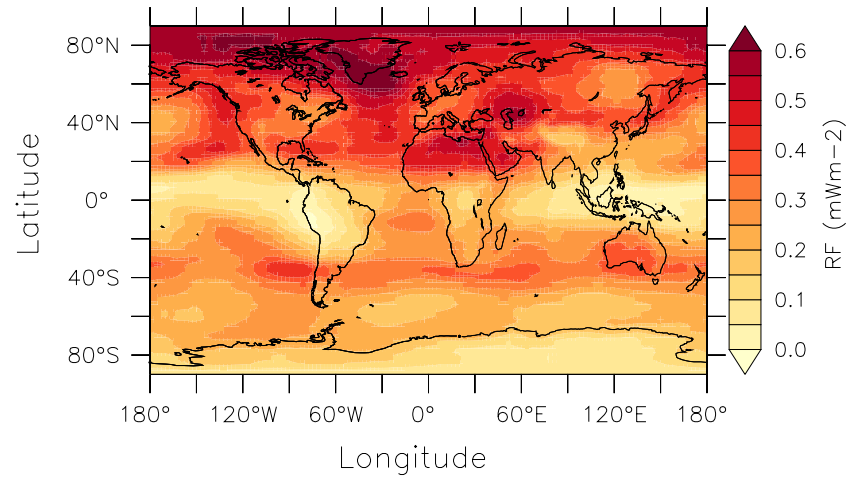

Figure S1. Annual mean maps of net ozone radiative forcing (Ltn_Mth-Cnt) calculated using a) the radiative kernel (RK) technique and b) the SOCRATES radiative transfer model (RTM). The annual and global mean is shown on the top $\left(\mathrm{mWm}^{-2}\right)$. 


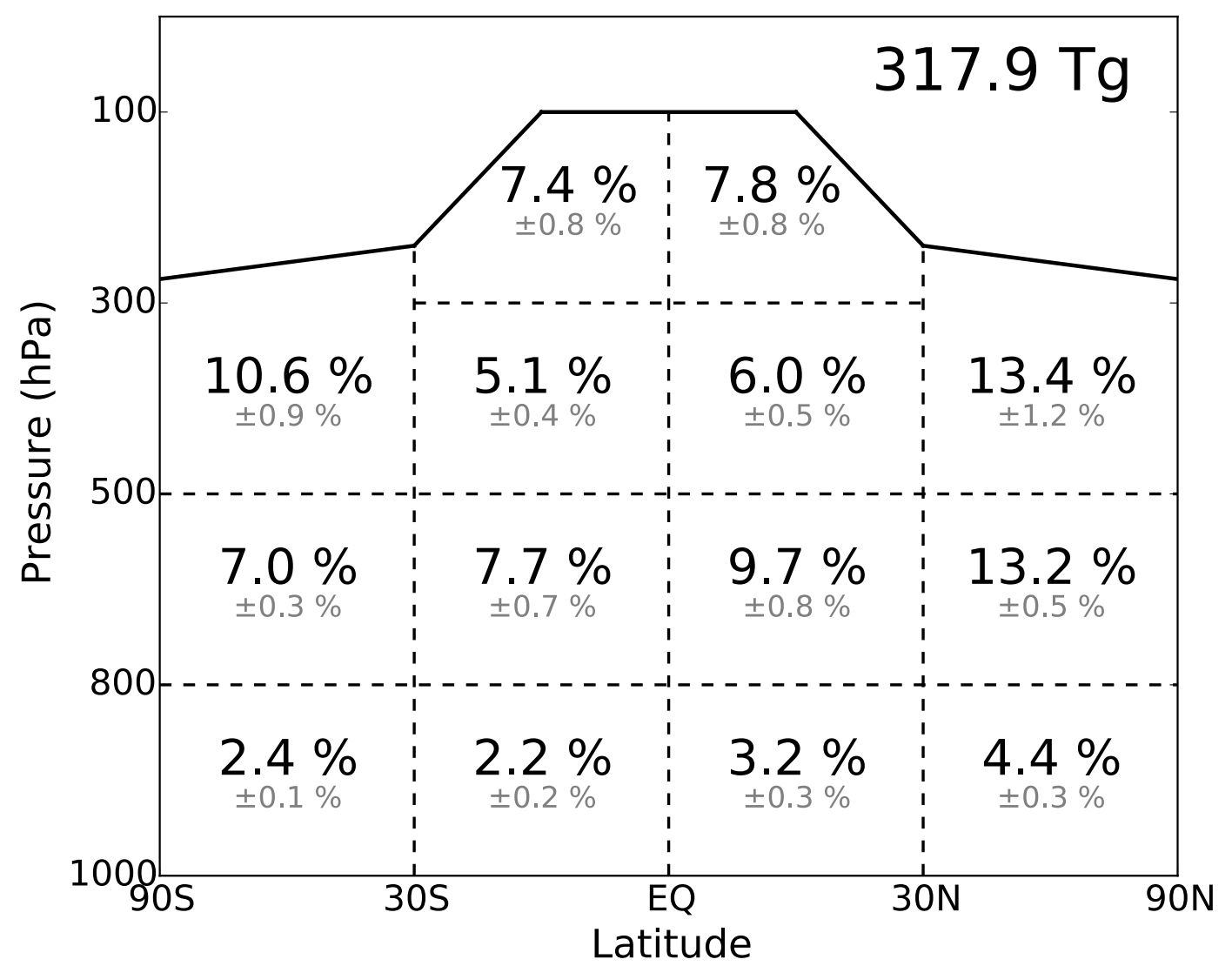

Figure S2. Present-day (Cnt) annual mean tropospheric ozone burden distribution (black) and the \pm 1 standard deviation (grey), represented by "boxes" (dashed black lines) of approximately equal air masses, as per Young et al. (2013). The tropopause is represented by the black thick line (i.e. regions below $150 \mathrm{ppb}$ ozone levels). The annual and global tropospheric ozone burden mean is shown in the top right corner. 


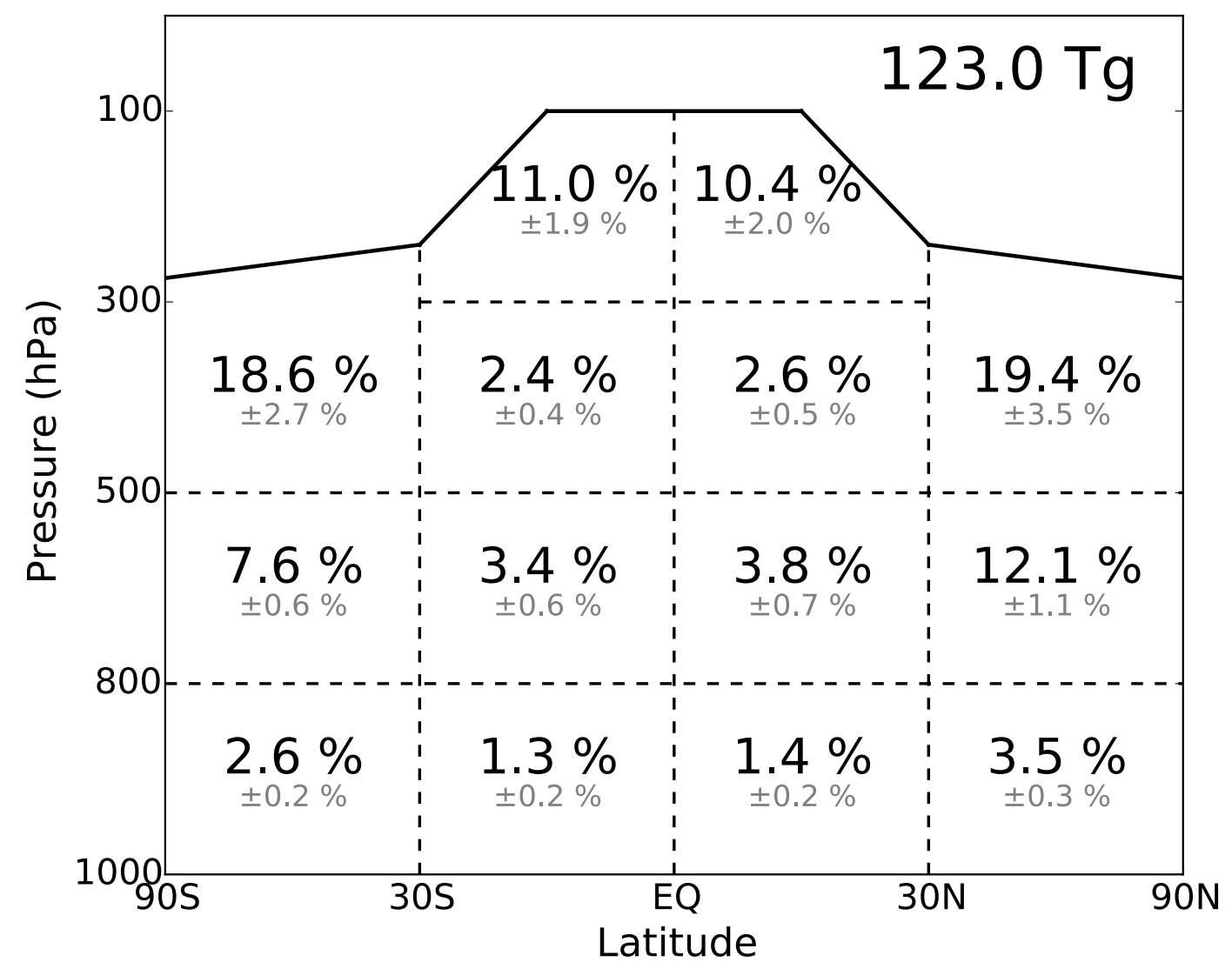

Figure S3. Same as Fig. S2 but for stratospheric ozone tracer (O3S). 


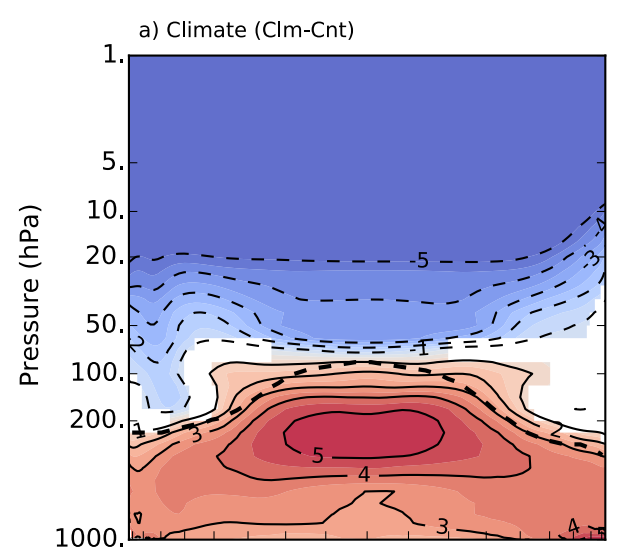

b) Lightning (Ltn-CIm)

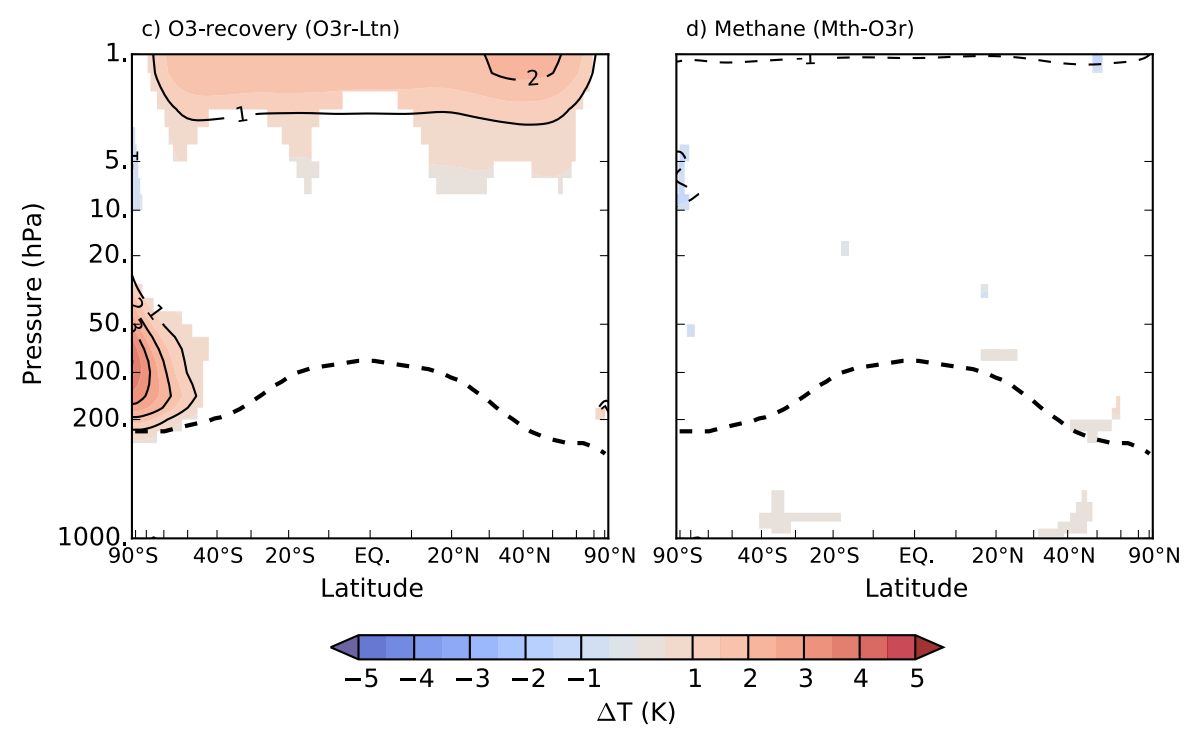

Figure S4. Same as Fig. 3 in the main text, but for temperature (K). 


\section{References}

Edwards, J. M., and Slingo, A.: Studies with a flexible new radiation code. I: Choosing a configuration for a large-scale model, Quart. J. Roy. Meteor. Soc., 122, 689-719, doi:10.1002/qj.49712253107, 1996.

Young, P. J., Archibald, A. T., Bowman, K. W., Lamarque, J. F., Naik, V., Stevenson, D. S., Tilmes, S., Voulgarakis, A., Wild, O., Bergmann, D., Cameron-Smith, P., Cionni, I., Collins, W. J., Dalsoren, S. B., Doherty, R. M., Eyring, V., Faluvegi, G., Horowitz, L. W., Josse, B., Lee, Y. H., MacKenzie, I. A., Nagashima, T., Plummer, D. A., Righi, M., Rumbold, S. T., Skeie, R. B., Shindell, D. T., Strode, S. A., Sudo, K., Szopa, S., and Zeng, G.: Pre-industrial to end 21st century projections of tropospheric ozone from the Atmospheric Chemistry and Climate Model Intercomparison Project (ACCMIP), Atmos. Chem. Phys., 13, 2063-2090, doi:10.5194/acp-13-2063-2013, 2013. 